\title{
Social Media and the Fear of Missing Out: Scale Development and Assessment
}

\author{
Jessica P. Abel, Beech-Nut, USA \\ Cheryl L. Buff, Siena College, USA \\ Sarah A. Burr, Ipsos, USA
}

\begin{abstract}
For many, viewing social media causes them to relate their own lives to what they are seeing or reading, resulting in feelings that they are somehow missing out. It is suggested that the fear of missing out influences decision making and behavior. The current research explores the measurement of FOMO, focusing on scale development and validation. Using extant scales for inadequacy, irritability, anxiety, and self-esteem, a list of items ( $n=37$ ), postulated to measure FOMO, was created. In addition to the scale items, questions to assess behavioral and demographic characteristic were included. A pre-test of the survey instrument was conducted $(n=30)$. The final survey was administered electronically, resulting in a useable sample of $n=202$. Principal components analysis resulted in a 10 item, 3-factor solution explaining 71\% of the overall variance. The three factors performed reasonably well all with Cronbach's alpha above or near Nunnally's suggested .70 (Nunnally, 1978). Using the newly created scale, FOMO scores were calculated for each respondent. Results suggest significant differences in social media consumption across levels of FOMO. Results also suggest significant differences in the use of particular social media based on one's level of FOMO. Limitations include the sample and it is suggested that future research, including confirmatory factor analysis, should be conducted.
\end{abstract}

Keywords: Self-Esteem; Social Media; Anxiety; Irritability; Feelings of Inadequacy; Fear of Missing Out

\section{INTRODUCTION}

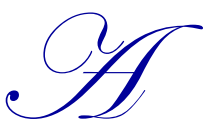
s social animals, people tend to have a desire to belong to social groups. Today, these groups exist in both physical and virtual varieties. In either case, the need to understand what members of the group are doing at a particular point in time bears importance to each individual. How important it is, and how motivated one is to find out what others in the group, or on the periphery of the group, are doing varies. Indeed, more attention is being given to this as the numbers of virtual connections individuals have increases. The fear of missing out (FOMO) is defined as the "uneasy and sometimes all-consuming feeling that you're missing outthat your peers are doing, in the know about, or in possession of more or something better than you" (JWT Marketing Communications, 2012, p. 4). Essentially, the fact that people care deeply about what others do and think ties into feeling left out, fearing what others may think of our lives (JWT Marketing Communications, 2012).

While FOMO is not an entirely new concept, the intensity and discussion of FOMO has significantly increased with the rise of technology-namely social media. A recent study done by JWTIntelligence Communications found nearly $70 \%$ of adults admit to experiencing feelings of missing out (JWTIntelligence, 2012). Wortham (2011) suggests that FOMO has been present throughout history in any communication channel that would allow individuals to gain knowledge of their friends, family, or even strangers' lives. These communication channels include newspapers, letters, pictures, annual holiday newsletters and emails (Wortham, 2011). Improvements in technology, as well as simpler access to technology, have made receiving information easier and as such arguably more addictive than ever. Instead of reading the news about parties or events every once and a while (i.e., in a weekly or even daily newspaper), we have the ability to receive electronic information instantaneously through the tool of our choosing (a smartphone, tablet, laptop, etc.). Simple access to this information via technology can potentially motivate individuals to easily compare their own lives to the lives they read about through postings online and observations through pictures on social media sites-causing them to feel less satisfied with their lives and behaviors. 
What is the basis for FOMO? It has been suggested that when individuals feel they are missing out, they are experiencing feelings of irritability, anxiety, and inadequacy. What is less clear is whether an underlying predisposition to irritableness, anxiousness, and feelings of inadequacy lead to higher levels of FOMO. Further, one's self-esteem may also impact the level of FOMO that is experienced. However, a measure of FOMO operationalized with these particular variables, essentially the underlying psychological characteristics that might influence ones' level of FOMO, does not exist. Thus, the current research proposes and evaluates a scale construct for measuring FOMO.

\section{LITERATURE SEARCH}

As articulated above, there have been changes in technology, namely social media, which appear to fan the fire of FOMO. Thus understanding the developments and impact of social media is critical to our understanding of FOMO. So too is an understanding of the personal, psychological, and situational characteristics that undergird FOMO.

\section{Inadequacy, Irritability, Anxiety \& Self-Esteem}

Past research has indicated that FOMO is comprised of irritability, anxiety, and feelings of inadequacy, with individual's feelings of irritability, anxiety, and inadequacy intensified when they view social media (JWTIntelligence 2012; Wortham, 2011). It is also suggested that self-esteem may impact the level of FOMO that one experiences. The psychological traits, states, and factors that are present when one is using social media are the fundamental building blocks in helping us to understand FOMO.

Inadequacy, frequently viewed as shame and incompetence, is the experience of being exposed to a situation where the self is seen as lesser in some regard (Seu, 2006). Feelings of incompetence exist on a continuum from inadequacy through insecurity to complete incompetence (Seu, 2006). In seminal work on feelings of inadequacy Solomon (1928) noted that the feeling of inadequacy can lead to the feeling of inferiority. Subsequent research has supported the link between feelings of inadequacy and stress (Gould, Horn \& Spreeman, 1983). Business research exploring feelings of inadequacy is limited, yet it is not difficult to imagine how this concept might contribute to the proposed fear of missing out. When an individual hears or reads about an event they were not invited to, or sees someone in possession of a product they wish they had, it is plausible that they would start to feel inadequate about themselves wondering, for example, why weren't they invited? Why couldn't or didn't they purchase that product? This may impact self-esteem as well.

An individual with a higher level of irritability would have the tendency to assume a more hostile attitude, act impulsively or rudely at the slightest frustration or at the smallest disagreement (Caprara et al., 1985). Buss and Durkee (1957) described it similarly as an inclination to explode with negative feelings at the slightest aggravation, including a quick temper, grouchiness, and rudeness. Both concepts describe an individual who, in a provoking situation, is prone to negative thoughts and outbursts (Godlaski \& Giancola, 2009). Here again, limited research in the business literature is noted. Considering irritability in the present context, when an individual begins to feel fearful, apprehensive, and uneasy upon checking social media sites, their irritability and anxiety may temporarily increase. Anxiety research has typically divided anxiety into two categories based on whether researchers are interested in long-lasting or transient anxiety: trait anxiety and state anxiety. Trait anxiety refers to either an individual's general disposition to become anxious or their typical level of anxiety, whereas state anxiety is usually defined as a person's level of anxiety over relatively short periods of time frames (seconds, minutes, and hours) (Wilt, Oehlberg, \& Revelle, 2011). It is proposed that state anxiety is most relevant to FOMO, as it is most likely that individuals with this fear after viewing social media will temporarily become more anxious when unable to do so.

Social exclusion and ostracism can also play key roles in the fear of missing out as they impact the factors that are suggested to underlie FOMO, namely anxiety and self-esteem. Considerable research has been conducted in the area of ostracism (Eisenberger, Lieberman \& Williams 2003; Williams, 2001, Williams, Cheung \& Choi, 2000; Zadro, Williams, \& Richardson, 2004) and social exclusion (Twenge, Baumeister, Tice, \& Stucke, 2001; Twenge \& Campbell, 2003; Twenge, Catanese, \& Baumeister, 2003). Williams' (2001) need-threat model of ostracism notes that being excluded and ignored can hinder desires of belonging, self-esteem and meaningful existence. According 
to Baumeister and Leary's (1995) belongingness theory, social exclusion causes anxiety because it signals an actual loss of belonging. The fear of social exclusion and the fear of ostracism may motivate people to conform to groups largely in an attempt to avoid either or both social exclusion and ostracism. Additionally, social comparison theory suggests that people decide their own personal worth based on how they compare to others (Festinger, 1954). Especially in situations of uncertainty, people will compare themselves to others, and evaluate themselves based on the results (Festinger, 1954).

Self-esteem represents the affective, or evaluative, component of the self-concept; it signifies how people feel about themselves (Leary \& Baumeister, 2000). Low self-esteem has been found to be a risk factor for social anxiety and depression (Sowislo \& Orth, 2012). According to DeJong et al. (2012), there are two major facets of self-esteem: implicit and explicit self-esteem. Explicit self-esteem entails conscious reflective self-evaluation whereas implicit self-esteem deals with an individual's ability to evaluate themselves in an unconscious fashion (De Jong et. al 2012). DeJong et al. (2012) report an association between low implicit self-esteem and social anxiety, especially for females. There is extensive literature suggesting a positive correlation between low self-esteem and high levels of anxiety (De Jong, Sportel, de Hullu \& Nauta, 2012; Hulme, Hirsch, \& Stopa, 2012; Schriber, Bohn, Aderka, Stangier, \& Steil, 2012). It is not difficult to imagine situations where feelings of being satisfied and/or dissatisfied with oneself would be amplified after viewing social media.

\section{Fear of Missing Out (FOMO)}

As mentioned, past research indicates FOMO is comprised of irritability, anxiety, and feelings of inadequacy, with these feelings tending to worsen when an individual logs on in to social media websites (Wortham, 2011). Intense feelings of one "missing out" have the power to influence buying decisions; an individual could chose to buy a better or more expensive product than their friend because they don't want to miss out on the possibility of having something better or missing out on an opportunity to "fit in." In situations like this, people may change what they typically do or purchase because of social pressures and fear of being excluded (Dykman, 2012). We may not always consciously realize that we're participating because we're afraid of missing out on something, but we can relate to considering going to a party or event because other people thought that we should go instead of going because we truly wanted to (Dembling, 2011). People enjoy being "in the know"; according to a recent survey done by JWTIntelligence (2012), 83\% of respondents stated they feel their lives are in overdrive-that there is too much to do, read, buy, and watch, to the point that it is overwhelming. Despite feelings that there is simply too much data out there to consume and understand, people still continue to try to absorb as much as possible. This constant connection to information through social media can cause people to feel worse about not staying up to speed on what others are saying, doing, and even buying.

Today, FOMO can feel like an overwhelming urge to be in two or more places at once, fueled by the fear that missing out on something could put a dent in your happiness (JWTIntelligence, 2012). Social media is "like kerosene on FOMO's fire" (Miller, 2012, p. 2). Now that any individual has the ability to see other's updates on their lives in real time, social media and technology enable consumers to have constant access to what they are missing out on (i.e., a party, a dinner, a new career, or other opportunity). Being constantly connected to social media and always being able to view the things you're missing out on can cause individuals to begin to experience feelings of dissatisfaction, anxiety, and unworthiness (Miller, 2012). Individuals have a tendency to become more anxious, irritable, feel more inadequate and have temporarily lower self-esteem after viewing social media (JWTIntelligence, 2012). With the younger generations' constant connection to their friends' social media updates, it is almost impossible not to know what other people are doing and saying at all times.

According to a recent survey by JWTIntelligence (2012), roughly $40 \%$ of individuals from 12-67 say that social media has increased their fear of missing out. Only $8 \%$ of this survey's respondents had heard of FOMO. Once FOMO was explained in the study, $70 \%$ of adult millennials (18-34 year olds) said they could completely or somewhat relate to the concept. FOMO has the potential to drive spending, since it heightens participation on social media platforms and motivates consumers to do more (JWTIntelligence, 2012). The JWTIntelligence (2012) study exposed how prevalent the understanding and feelings of FOMO are as measured by a single question. 
Of note are the results related to adult millennials, ages 18-34. Seventy percent of adult millennials admitted that they could relate to the idea of FOMO (the highest percentage out of any generation). Similarly, $36 \%$ of adult millennials acknowledged that they experience FOMO often or sometimes. Most notably, $46 \%$ of adult millennials noted that any fear of missing out they do have has been amplified by their social media use (JWTIntelligence, 2012). Nearly 8 in 10 people believe that people use social media to brag about who they are and what they do (Laird, 2012).

\section{Social Media}

Social media's presence in our lives is becoming inescapable. Communicating through social media may be one of the most popular methods of electronic communication. Social media sites and blogs dominate Americans time online, now accounting for nearly one quarter of their total time spent on the Internet (Nielsen, 2011). Americans spend more time on Facebook than on any other website (Nielsen, 2011). Not surprisingly, companies constantly bombard people with information about "liking" or "following" them on some social media platform. In social settings, it can be even more challenging to go more than a few hours without hearing a friend or other individual talk about what they posted, liked, or read on a social media site. For many, college students in particular, usage of social media is a habitual and arguably addictive behavior. Social networking sites can mean a new channel for communication, knowledge, entertainment, and even self-expression (Kim, Jeong, \& Lee, 2010).

The most popular social media or social networking sites today in order of popularity are Facebook, LinkedIn, Pinterest, Twitter and Instagram (Duggan \& Smith, 2013a). These social media sites are the most useful for the current research, as they are popular among college students in the United States and have the greatest number of users. Individuals have various motivations for using social media sites and each of these social networks has unique capabilities and offerings that satisfy users. Of note, these programs have features which encourage users/members to disclose personal information and share it with others. The reach of these programs cannot be overlook. Seventyone percent of online adults are Facebook users and it is typically the social networking site of choice (Duggan \& Smith, 2013b). Twitter has a different social structure than Facebook, as it is more public and messages spread in a form of broadcasting. As of April 2014, Twitter has 255 million average monthly active users in the United States, and 29\% of millennials (ages 15-34) use Twitter (Smith, 2014). Pinterest is a picture-sharing social media platform based on collections and themes. As of September 2013, 21\% of online adults use Pinterest; however women are four times more likely than men to be users (Duggan \& Smith, 2013). Instagram is another ideal platform for sharing photos and is increasingly popular. Nearly doubling the number of users within one year, as of March 2014 there were 200 million active users on this social networking site (Bennett, 2014). The use of LinkedIn and Google + , largely for professional purposes, continues to grow.

It is also important to note the evolution of use of these various social media platforms. While Facebook has always ranked first in popularity, youth today have different opinions of which social network they prefer. As of an April 2014 study, teens ranked Instagram as the most important social network, followed by Twitter and then Facebook (MarketingCharts staff, 2014). This, and the growth of other platforms such as Snapchat and Vine, is proof of the dynamic nature of social networking.

\section{Social Media and FOMO}

Social media sites play an essential role in the fear of missing out. While it is possible that FOMO has existed for as long as communication channels have existed, there is no doubt that social media's presence in our lives has amplified the need and desire (and opportunity) to know what other people are doing and saying at all times. Because information is more readily available than ever before (now people don't even need to be at their computers to access this data, as many people access social media on mobile devices), it is suggested that people have become more addicted to consuming information through social media. Social media gives people opportunities to easily share information with others and provides them the constant opportunity to check what other people are doing and saying. This raises a few questions. Does increased checking of social media result because one has FOMO, or does increased checking of social media cause FOMO...or some combination thereof? Do higher levels of FOMO result in a decrease in checking social media because the individual is afraid of missing out and wants to avoid additional pain to the psyche? Testing these questions is predicated on the ability to measure FOMO. 


\section{MEASURING FOMO}

While FOMO is not an entirely new concept, there are seemingly limited means for measuring it. As previously noted, JWT Intelligence (2012) administered a survey to assess the prevalence of FOMO. In their study, they first asked respondents how well they could identify with the fear of missing out without providing respondents with any definition of the fear of missing out. After this initial response, respondents were then given an informal explanation of FOMO and asked how well they could identify with these feelings. There was no indication in that report of FOMO measured as a construct; alternatively, it appears that FOMO was measured by response to a single question.

Pryzbylski et al. (2013) conducted a series of studies, the first of which focused on the development of a scale to measure FOMO. In addition, a later study used a modified version of the Przybylski et al. (2013) to explore the extent to which people check their mobile phones out of a fear of missing out. The resulting "C-FoMO" scale used to investigate whether FOMO is a motivator for regular mobile phone checking (Haeto, 2013).

The current research focuses on scale development using foundational items, namely psychological components, which have been associated with FOMO in previous writings: inadequacy, anxiety, irritability, and self-esteem. Essentially, someone higher in feelings of inadequacy, higher in feelings of anxiety, higher in feelings of irritability, and lower in self-esteem is envisioned to have a higher fear of missing out. This is distinct from Przybylski et al. (2013) who drafted items "to reflect the fears, worries, and anxieties people may have in relation to being in (or out of) touch with the events, experiences, and conversations happening across their extended social circles." (p.1842). Thus the current research focuses on measuring psychologically based FOMO, whereas Przybylski et al. (2013) have developed a more situation based scale.

\section{Methodology}

Consistent with Churchill (1979) and other marketing scholars' (Churchill, 1979; DeVellis, 2003; Netemeyer, Bearden, \& Sharma, 2003; Williams, Ponder \& Autry, 2009; Wood \& Winston, 2007) guidelines to scale development, the first step was specifying the domain of the construct, the fear of missing out. Using the psychological components listed above, a review of extant scales was undertaken. Scales were reviewed and evaluated based on intended use and past research results associated with its use. Ultimately, four existing scales were selected as a starting point. Selected scales include the Feelings of Inadequacy Scale created by Janis and Field (1959), a shortened 6 item version of the State Trait Anxiety Inventory, created by Spielberger et al. and shortened by Abed, Hall, and Moser (2012), and the Irritability Questionnaire by Craig, Hietanen, Markova, and Berrios (2006). Finally, since the current study focuses on explicit self-esteem, the Self-Esteem Scale by Rosenberg (1965) was used.

All items from each scale were combined and evaluated $(n=73)$ by the authors, with redundant items deleted. Additional modifications were made to items in an effort to modernize the item wording and to incorporate a social media focus. This resulted in 37 items purported to represent FOMO. All items were assessed using an 8-point Likert type scale, verbally anchored with "never" to "always".

The FOMO scale, with initial scale items, was pre-tested using a paper and pencil survey administered to a sample of college students from a private college in the Northeast $(n=30)$. In addition to the scale items, questions to assess how frequently individuals view social media, self-reported degree of fear of missing out, and the urge to check social media were included.

Changes were made to the survey based on the results of interviews with pretest participants, comments respondents added to their completed surveys, and a review of the survey results. These changes were minor and dealt primarily with question wording and order.

Final changes were incorporated into the survey and implemented in the online survey tool, Qualtrics. Surveys were distributed through email and various social media platforms including Facebook and LinkedIn. Additionally, all individuals who received the survey link were encouraged to share it with others. 


\section{Participants}

A total of 232 individuals responded to the survey, of which 202 responses were useable. The final sample ( $\mathrm{n}=202$ ) was largely millennials, with the majority being college students, and appropriately sized for scale development with over 200 respondents. As suggested by DeVellis (2003), the sample contained more than 5 participants for each proposed scale item.

\section{Analysis}

Data was exported to SPSS (11.0) for data analysis. Data analysis included exploratory factor analysis, reliability testing, frequency analysis, and ANOVA testing.

\section{RESULTS}

The initial goal, and our primary research question, was to determine whether a valid measure of FOMO can be developed. Additionally, we sought to understand the differences in FOMO with respect to the socio-demographic characteristics of our sample.

\section{Sample}

The sample was comprised of 202 respondents, of which 196 reported gender. Of those reporting, 68\% ( $\mathrm{n}=133$ ) were female and $32 \%(\mathrm{n}=63)$ were male. As the survey was distributed primarily on college campuses, respondents were asked to indicate class year. A majority $(38 \%, n=75)$ was seniors, with many respondents falling in the $20-21$ $(42 \%, \mathrm{n}=81)$ age range. With regard to the frequency of checking social media, we note fairly even distribution around 1-4 times a day (25\%), 5-9 times a day (29\%), and 10-15 times a day (26\%). Surprisingly, 10\% check 20-29 times a day and over $7 \%$ check more than 30 times a day. Continuing the evaluation of behavioral characteristics associated with social media usage, $37 \%$ indicate that they use/view/participate/contribute to/encounter social media 5-9 minutes each time they use/view/participate/contribute to/encounter it on a daily basis. Twenty-four percent indicated that they use social media less than 5 minutes each time they access it.

\section{Development and Validation of an Instrument Assessing FOMO}

Principal components analysis with an oblique rotation using oblimin was used to evaluate the initial 37 scale items. Although more difficult to interpret, oblimin rotation was used to allow for correlated factors. The Kaiser-MeyerOlkin value was .783 exceeding the recommended value of .6 and Bartlett's Test of Sphericity reached statistical significance, supporting the factorability of the correlation matrix (Pallant, 2010). As a first step, factors with eigenvalues below one were eliminated. Additionally, items with factor loadings equal to or below .5 were eliminated. Finally, all remaining items were assessed based on what factors they loaded on to, with the goal of having each item load primarily on one component as suggested by DeVellis (2003).

Initially, factor analysis revealed a 12-factor solution. By eliminating items that loaded strongly across multiple components and eliminating factors that demonstrated poor reliability estimates, the final analysis resulted in a 3factor solution. A total of $71 \%$ of the overall variance was explained. Specifically, component 1 explained $42 \%$ of the variance, component 2 explained $15 \%$ of the variance and component 3 explained $14 \%$ of the variance (as shown in Table 1 below). 
Table 1. Total Variance Explained

\begin{tabular}{|c|c|c|c|c|c|c|}
\hline \multirow{2}{*}{ Component } & \multicolumn{3}{|c|}{ Initial Eigenvalues } & \multicolumn{3}{|c|}{ Extraction Sums of Squared Loadings } \\
\hline & Total & $\%$ of Variance & Cumulative \% & Total & $\%$ of Variance & Cumulative \% \\
\hline 1 & 4.151 & 41.514 & 41.514 & 4.151 & 41.514 & 41.514 \\
\hline 2 & 1.500 & 14.998 & 56.512 & 1.500 & 14.998 & 56.512 \\
\hline 3 & 1.422 & 14.217 & 70.729 & 1.422 & 14.217 & 70.729 \\
\hline 4 & 689 & 6.892 & 77.621 & & & \\
\hline 5 & .564 & 5.644 & 83.265 & & & \\
\hline 6 & .503 & 5.032 & 88.297 & & & \\
\hline 7 & .465 & 4.651 & 92.948 & & & \\
\hline 8 & .344 & 3.440 & 96.388 & & & \\
\hline 9 & .227 & 2.266 & 98.655 & & & \\
\hline 10 & .135 & 1.345 & 100.000 & & & \\
\hline
\end{tabular}

The component matrix is presented in Table 2 below.

Table 2. Component Matrix

\begin{tabular}{|c|c|c|c|}
\hline & 1 & 2 & 3 \\
\hline I take a positive attitude toward myself & .95 & & \\
\hline On the whole, I am satisfied with myself & .93 & & \\
\hline I feel that I have a number of good qualities & .75 & & \\
\hline I am inclined to feel that I am a failure & .73 & & \\
\hline I feel that I do not have much to be proud of & .71 & & \\
\hline $\begin{array}{l}\text { When in a group of people, do you have trouble thinking of the right } \\
\text { things to talk about?? }\end{array}$ & & .85 & \\
\hline How frequently are you troubled by shyness? & & .83 & \\
\hline Do you feel uncomfortable meeting new people & & .64 & \\
\hline $\begin{array}{l}\text { Assume you are unable to check social media when you want to...how } \\
\text { frequently do you feel frightened? }\end{array}$ & & & .94 \\
\hline $\begin{array}{l}\text { Assume you are unable to check social media when you want to...how } \\
\text { frequently do you feel nervous? }\end{array}$ & & & .93 \\
\hline
\end{tabular}

Reliability analysis was performed on the resulting 3 components. Consistent with suggestions from Nunnally (1978, p. 245), factors with a Cronbach's alpha above .70 were sought (Nunnally, 1978). As shown in Table 3 below, two factors met that level of acceptability. A third factor fell slightly below the desired level at .69. The resulting proposed scale contains 10 items as presented in Table 4.

Table 3. Reliability Analysis

\begin{tabular}{|c|c|c|}
\hline & Cronbach's Alpha & Number of Items \\
\hline Component 1: "Sense of Self/Self Esteem" & .88 & 5 \\
\hline Component 2: "Social Interaction/ Extroversion" & .69 & 3 \\
\hline Component 3: "Social Anxiety" & .85 & 2 \\
\hline
\end{tabular}

Table 4. Fear of missing out proposed scale

\begin{tabular}{l}
\hline \multicolumn{1}{c}{ Never $-\ldots-\ldots$ Always } \\
\hline 1. I take a positive attitude toward myself* \\
2. On the whole, I am satisfied with myself* \\
3. I feel I have a number of good qualities* \\
4. All in all, I am inclined to feel that I am a failure \\
5. I feel I do not have much to be proud of \\
6. Do you feel uncomfortable meeting new people? \\
7. How frequently are you troubled by shyness? \\
8. When in a group of people, do you have trouble thinking of the right things to talk about? \\
9. Assume you are unable to check social media when you want to. Generally, how frequently do you feel frightened? \\
10. Assume you are unable to check social media when you want to. Generally, how frequently do you feel nervous? \\
*Indicates reverse scored item
\end{tabular}

*Indicates reverse scored item 


\section{Testing FOMO}

The next step was to evaluate socio-demographic characteristics and FOMO; see Table 5 below. Composite FOMO scores were calculated for each subject. This was achieved by summing the responses to the 10 scale items. Total FOMO scores could range from 10 to 80 . Questions related to frequency of use, urge to use, and duration of use of social media were evaluated. Lack of response to usage questions by some survey participants resulted in $n=185$. Using a total score of 45, the midpoint on the total FOMO score scale, the sample tended to be lower in FOMO (low FOMO $<=45, \mathrm{n}=174$; high FOMO $>45, \mathrm{n}=11$ ).

Evaluating gender and FOMO, we note no significant finding. The average total FOMO score for women was just slightly higher than that reported by men. Age results suggest a significant drop off in overall FOMO for those "Over 24", with younger individuals expressing higher FOMO. As the sample was largely college students, we additionally sought to understand the relationship between GPA and FOMO. Those with the lowest GPA also demonstrate the lowest overall FOMO score. Various GPA categories between the high and low GPA endpoints show relatively similar levels of FOMO. "Freshmen" express low overall FOMO while "Juniors" display the highest.

Table 5. Demographic Characteristics and FOMO

\begin{tabular}{|c|c|c|}
\hline Demographic Variable & Total or Mean FOMO Score & Significance at $p<.05$ \\
\hline Gender & $\begin{array}{l}\text { FOMO }(\text { Women })=28.4 \\
\text { FOMO }(\text { Men })=27.8\end{array}$ & Not significant \\
\hline Age & $\begin{array}{l}\text { FOMO(Age 18-19) }=28.8 \\
\text { FOMO }(\text { Age 20-21) }=28.9 \\
\text { FOMO }(\text { Age 22-23) }=30.9 \\
\text { FOMO }(\text { Over 24) }=22.8\end{array}$ & $\begin{array}{c}\text { Significant } \\
\mathrm{F}=4.266, \mathrm{p}=.006\end{array}$ \\
\hline GPA & $\begin{array}{l}\text { FOMO }(\text { GPA 2.0-2.49) }=25.8 \\
\text { FOMO }(\text { GPA 2.5-2.99) }=29.7 \\
\text { FOMO }(\text { GPA 3.0-3.49) }=29.2 \\
\text { FOMO }(\text { GPA 3.5-3.89) }=28.7 \\
\text { FOMO (GPA “Above 3.89”) }=31.5\end{array}$ & $\begin{array}{c}\text { Not significant } \\
\mathrm{F}=1.915, \mathrm{P}=.094\end{array}$ \\
\hline Class Year & $\begin{array}{l}\text { FOMO }(\text { Freshman })=23.8 \\
\text { FOMO }(\text { Sophomore })=31.5 \\
\text { FOMO }(\text { Junior })=29.9 \\
\text { FOMO }(\text { Senior })=28.7\end{array}$ & $\begin{array}{c}\text { Significant } \\
\mathrm{F}=2.504 ; \mathrm{p}=.032\end{array}$ \\
\hline
\end{tabular}

Exploring the relationship between situations associated with the use of social media and manifested levels of FOMO, summarized in Table 6; we note some differences in the urge to check social media. The urge to check social media, measured on a 7 point Likert scale with verbal anchors of "Very weak" to "Very strong", was evaluated across four situations. Results suggest significant differences between High FOMO (HFOMO) and Low FOMO (LFOMO) with "Urge to check social media 'when you're with others, 'when you are unable to log on for any reason', and 'when you're in class'. There was no significant difference with "urge to check social medial when you're alone", with those both high and low in FOMO expressing a stronger urge to check their social media account(s) than in all other situations presented.

Table 6. Social Media Usage Urges across Manifested High/Low FOMO

\begin{tabular}{l|l|l|c}
\multicolumn{4}{c}{ Table 6. Social Media Usage Urges across Manifested High/Low FOMO } \\
\hline \multicolumn{1}{c|}{ Social Media Usage Situation } & \multicolumn{1}{c}{ High FOMO } & Low FOMO & Significance at $\mathbf{p}<.05$ \\
\hline $\begin{array}{l}\text { Urge to check social media when } \\
\text { you're with others. }\end{array}$ & $\mu(\mathrm{HFOMO})=4.18^{*}$ & $\mu(\mathrm{LFOMO})=3.98$ & $\begin{array}{c}\text { Significant } \\
\mathrm{F}=4.969, \mathrm{p}=.027\end{array}$ \\
\hline $\begin{array}{l}\text { Urge to check social media when } \\
\text { you are unable to log on for any } \\
\text { reason. }\end{array}$ & $\mu(\mathrm{HFOMO})=5.36$ & $\mathrm{~S}=6.33$ & $\mathrm{~F}=6.166, \mathrm{p}=.014$ \\
\hline $\begin{array}{l}\text { Urge to check social media when } \\
\text { you're in class. }\end{array}$ & $\mu(\mathrm{HFOMO})=4.64$ & $\mu(\mathrm{LFOMO})=3.07$ & $\mathrm{~S}$ \\
\hline $\begin{array}{l}\text { Urge to check social media when } \\
\text { you're alone. }\end{array}$ & $\mu(\mathrm{HFOMO})=5.45$ & $\mu(\mathrm{LFOMO})=5.36$ & $\mathrm{~F}=8.164, \mathrm{p}=.00-59$ \\
\hline
\end{tabular}

Urge to check measured on a 7 point Likert scale with verbal anchors of 1 = "Very weak" to 7 = "Very strong". 
Results additionally demonstrate significant differences in the number of times that social media is checked during a day, with those higher in FOMO more frequently checking Facebook $(\mathrm{F}=12.9, \mathrm{p}=.000)$, Twitter $(\mathrm{F}=15.5, \mathrm{p}=.000)$, Instagram $(\mathrm{F}=10.4, \mathrm{p}=.001)$, and MySpace $(\mathrm{F}=12.6, \mathrm{p}=.000)$. Results were not significant for LinkedIn $(\mathrm{F}=.1 .6$, $\mathrm{p}=.206)$, Pinterest $(\mathrm{F}=.047, \mathrm{p}=.828)$, or Google $+(\mathrm{F}=2.4, \mathrm{p}=.124)$. There was also a significant result for "How often do you feel you have missed out after viewing social media?" with those higher in FOMO more likely to reflect this $(\mu(\mathrm{HFOMO})=5.09, \mu(\mathrm{LFOMO})=2.97, \mathrm{~F}=17.89, \mathrm{p}=.000)$. Of interest, when asked "I feel I am missing out when I check social media", measured on a 8 point Likert scale verbally anchored with Never and Always, those low in FOMO experience the feeling more frequently $(\mu(\mathrm{HFOMO})=4.55, \mu(\mathrm{LFOMO})=5.60, \mathrm{~F}=3.697, \mathrm{p}=.056)$.

To further refine the analysis of FOMO, we conducted additional testing. Recall that initial testing looked at High/Low FOMO using a scale midpoint as the cutoff for determining one's status. Using the binning feature of SPSS, subjects were divided, based on total FOMO scores, into 3 relatively equivalent bin sizes: Bin $1, n=65$, represented FOMO scores $<=23$; Bin 2, $\mathrm{n}=60$, represented FOMO scores 24-31; Bin 3, $\mathrm{n}=60$, represented FOMO scores of 32+. Again, we checked for differences in behaviors and urges, noting significant findings for urge to check social media (1) when alone $(\mathrm{F}=3.462, \mathrm{p}<.033)$, (2) when unable to $\log$ on (for any reason) ( $\mathrm{F}=11.057$, $\mathrm{p}<.000)$, and (3) when you're in class $(\mathrm{F}=11.973, \mathrm{p}<.000)$. There was no significant difference in the strength of the urge to check social media when alone; regardless of level of FOMO, the urge to check is strong and, in fact, as evidenced by mean scores, stronger than all other situations tested.

\section{DISCUSSION}

The primary goal of this research was to propose and validate a scale for measuring FOMO. The resulting 10-item scale contains 3 factors, named to reflect the items within. Component 1, labeled "sense of self", assesses an individual's perception of himself or herself. Component 2 was labeled "social interaction" as it assesses an individual's feelings toward interacting with others, their issues with shyness, and comfort level on talking with other members of a group. Finally, the third component assesses and is labeled "social anxiety" with a specific focus on anxiety caused by social media usage. Thus it appears that a FOMO scale comprised of psychological elements, mainly assessing how individuals view themselves and their achievements, how they interact with others, and their level of anxiousness specifically related to their social media usage, has been developed. We further tested the scale by evaluating individuals with varying levels of FOMO and their corresponding social media usage characteristics. Results suggest that those with higher levels of FOMO are more likely to experience urges to check social media across situations. They are more likely to check Facebook, Twitter, Instagram, and MySpace. There is no difference in frequency of checking LinkedIn, which makes sense as this is primarily a social media platform for professional use. There was also no difference in frequency of checking Pinterest. The lack of significant findings for gender differs from earlier research as JWTIntelligence (2012) found that males were more likely to have a higher fear of missing out. With regard to GPS, perhaps not surprisingly those with low GPA have low levels of FOMO... arguably they may not be missing out on much as they redirect academic time to social time. The converse is true of our best academic performers who report higher levels of FOMO.

The practical and managerial implications are noteworthy. At its basic level, a scale to measure FOMO has interdisciplinary applications as a fundamental tool in understanding decision making and how, for example, people may make decision making errors because they fear they are missing an opportunity. As a discipline specific example, identifying the elements that define the fear of missing out and applying the construct will help marketers understand how FOMO might influence marketing analysis and the ultimate design of marketing strategy. It may impact market segmentation decisions and social media strategy. For example, many individuals form their opinions and feelings of a brand or product based on input from members of their social media network. By harnessing this power and further understanding FOMO, marketers may be able to utilize these feelings to drive purchase intentions and better understand consumers' motivations. With a deeper understanding of the relationship between social media habits and a consumer's degree of FOMO, marketers may have the ability to incorporate consumers' desire to belong as a motivational tool to purchase a product or seek out additional information. An understanding of FOMO might help in the design of social marketing strategies as well. Consider the success of the ALS Ice Bucket Challenge, largely driven through social media and resulting is a strong desire to participate as well as to send the challenge on to others 


\section{Limitations and Directions for Future Research}

There are limitations that should be addressed in subsequent research. First, as this was a sample of primarily college students, it would be appropriate to retest (confirmatory factor analysis) the scale with a larger and more diverse sample. This would further allow for additional review of Factor 2, "Social Interaction." Future research to understand cultural differences in FOMO is also warranted. So too is exploring the relationship between our measure of FOMO, that suggested by Przybylski et al. (2013), and those that are likely to follow. Based on the age results, we would expect that a broader sample would show that older individuals do not experience FOMO to the degree that younger individuals do. It would be interesting to explore the relationship between FOMO and other personality characteristics such as self-esteem and self-control. It is anticipated that with a broader sample, some of the media checking behavior and high/low FOMO findings would be consistent.

\section{CONCLUSION}

As the use social media becomes increasingly popular in today's society, the need to understand the relationship between FOMO and social media usage continues. The importance of knowing this relationship is fundamental to developing a better understanding of how marketers can interact and engage with millennials. It is also an important tool in understanding decision making and how decision making errors may be made because individuals fear they are missing out on an opportunity.

\section{AUTHOR BIOGRAPHIES}

Jessica Abel is an Associate Brand Manager at Beech-Nut Nutrition. At Beech-Nut, Jessica manages the base business for all of Beech-Nut's infant cereal as well as packaging, flavor, and other innovation for their infant cereal line. Jessica continues to apply the findings and expertise gained in marketing to millennials from this research in her management of all digital \& social media properties as well as the planning and execution of a unique advocacy program for Beech-Nut. She will be working toward her MBA in January 2016 at Union College.

Cheryl Buff, Ph.D. is the Associate Dean of the School of Business at Siena College. She is the former Director of the Center of Undergraduate Research and Creative Activity. Dr. Buff received the Excellence in Teaching Award from Siena College in 2010. She has authored a number of articles in the areas of consumer behavior, branding, social media, sports marketing and pedagogy, with publications in leading journals such as Journal of Business Ethics, Sport Marketing Quarterly, Journal of Product and Brand Management, and Marketing Management Journal.

Sarah Burr is a graduate from Siena College with a bachelor's degree in marketing and minor in psychology. She is currently employed as a research analyst for Ipsos Marketing in Norwalk, Connecticut.

\section{REFERENCES}

Abed, M.A., Hall, L.A., \& Moser, D.K. (2011). Spielberger's state anxiety inventory: Development of a shortened version for critically ill patients. Mental Health Nursing, 32 (4), 220-227.

Baumeister, R., \& Leary, M. (1995). The need to belong: Desire for interpersonal attachments as a fundamental human motivation. Psychological Bulletin, 117, 497-529.

Buss, A., \& Durkee, A. (1957). An inventory for assessing different kinds of hostility. Journal of Consulting and Clinical Psychology, 21, 343-349.

Caprara, G., Cinanni, V., D'Imperio, G., Passerni, S., Renzi, P., \& Travaglia, G. (1985). Indicators of impulsive aggression: Present status of research on irritability and emotional susceptibility scales. Personality and Individual Differences, 6 , 665-674.

Churchill, G. A. (1979, February). A paradigm for developing better measures of marketing constructs. Journal of Marketing Research, 16(1), 64-73.

Craig, K.J., Hietanen, H., Markova, I.S., \& Berrios, G.E. (2008). The irritability questionnaire: A new scale for the measurement of irritability. Psychiatry Research, 159(3), 367-375.

De Jong, P., Sportel, B., Hullu, E. d., \& Nauta, M. (2012, March). Co-occurrence of social anxiety and depression symptoms in adolescence: differential links with implicit and explicit self-esteem. Psychological Medicine, 42(3), 475-484.

Dembling, S. (2011, October 19). Fear of missing out: Why we say yes when we'd rather say no. Retrieved May 2012, from 
Psychology Today: http://psychologytoday.com/blog/the-introverts-corner/201110/fear-missing-out-why-we-say-yeswhen-wed-rather-say-no

DeVellis, R. F. (2003). Scale Development: Theory and Applications (Vol. 26). Thousand Oaks, California: Sage.

Dykman, A. (2012, March 21). The fear of missing out. Retrieved May 2012, from Forbes: http://www.forbes.com/sites/moneybuilder/2012/03/21/the-fear-of-missing-out/

Eisenberger, N. I., Lieberman, M. D., \& Williams, K. D. (2003, October 10). Does rejection hurt? An fMRI study of social exclusion. Science, 302, 290-292.

Festinger, L. (1954). A theory of social comparision processes. Human Relations, 7(117).

Gould, D., Horn, T.S., \& Spreeman, J. (1983). Sport psychology sources of stress in junior elite wrestlers. Journal of Sport \& Exercise Psychology, 5, 2, 159-171.

Godlaski, A. J., \& Giancola, P. R. (2009). Executive functioning, irritability, and alcohol-related aggression. Psychology of Addictive Behaviors, 23(3), 391-403.

JWT Marketing Communications. (2012, March 7). Fear Of Missing Out. Retrieved from JWT Intelligence: http://www.jwtintelligence.com/wp-content/uploads/2012/03/F_JWT_FOMO-update_3.21.12.pdf

JWTIntelligence. (2012, March). Fear of missing out (FOMO). Retrieved June 2012 , from JWT: http://www.jwtintelligence.com/wp-content/uploads/2012/03/F_JWT_FOMO-update_3.21.12.pdf

Kim, W., Jeong, O.-R., \& Lee, S.-W. (2010). On social Web sites. Information Systems, 35, $21 \overline{5}-236$.

Laird, S. (2012, June 24th). Mashable. Retrieved June 2012, from Do You Suffer From Social Media FOMO?: http://mashable.com/2012/06/22/fomo-infographic/

Leary, M., \& Baumeister, R. (2000). The nature and function of self-esteem: Sociometer theory. Advances in experimental social psychology, 32, 1-62.

Miller, S. (2012, June 24). Fear of missing out: Are you a slave to FOMO? Retrieved from ABC News: $\mathrm{http} / /$ abcnews.go.com/health/wellness/fear-missing-slave-fomo/story?id=16629972\&singlePage=true\#.T Tg48015.wF

Netemeyer, R. G., Bearden, W. O., \& Sharma, S. (2003). Scaling Procedures: Issues and Applications. Thousand Oaks, California: Sage Publications.

Nielsen. (2011). State of the Media: The Social Media Report.

Nunnally, J. (1978). Psychometric Theory (Vol. 2). New York: McGraw-Hill.

Rosenberg, M. (1965). Society and the Adolescent Self-Image. Princeton, NJ: Princeton University Press.

Seu, B. I. (2006). Shameful selves: Women's feelings of inadequacy and constructed facades. European Journal of Psychotherapy \& Counseling, 8(3), 285-303.

Solomon, M. (1928, January). The feeling of inadequacy. Welfare Magazine, 19.

Sowislo, J. F., \& Orth, U. (2012, June 25). Does Low Self-Esteem Predict Depression and Anxiety? A Meta-Analysis of Longitudinal Studies. Psychological Bulletin.

Twenge, J., \& Campbell, W. (2003). "Isn't it fun to get the respect that we're going to deserve?" Narcissism, social rejection, and aggression. Personality and Social Psychology, 29, 261-272.

Twenge, J., Baumesiter, R., Tice, D., \& Stucke, T. (2001). If you can't join them, beat them: Effects of social exclusion on aggressive behavior. Journal of Personality and Social Psychology, 81, 1058-1069.

Twenge, J., Catanese, K., \& Baumeister, R. (2003). Social exclusion and the deconstructed state: Time perception, meaninglessness, lethargy, lack of emotion, and self-awareness. Journal of Personality and Social Psychology, 85, 409423.

Williams, K. (2001). Ostracism: The Power of Silence. New York: Guilford Press.

Williams, K., Cheung, C., \& Choi, W. (2000). Cyberostracism: Effects of being ignored over the Internet. Journal of Personality and Social Psychology, 79, 748-762.

Williams, Z., Ponder, N., \& Autry, C. W. (2009). Supply chain security culture: measure development and validation. The International Journal of Logistics, 20(2), 243-260.

Wilt, J., Oehlberg, K., \& Revelle, W. (2011). Anxiety in personality. Personality and Individual Differences, 50, $987-993$.

Wood, J. A., \& Winston, B. E. (2007). Development of three scales to measure leader accountability. Leadership and Organization Devlopment Journal, 28, 167-185.

Wortham, J. (2011, April 9). Feel like a wallflower? Maybe it's your facebook wall. Retrieved May 2012, from New York Times: http://www.nytimes.com/2011/04/10/business/10ping.html

Zadro, L., Williams, K., \& Richardson, R. (2004). How low can you go? Ostracism by a computer lowers belonging, control, self-esteem, and meaningful existence. Journal of Experimental Social Psychology, 40, 560-567. 


\section{NOTES}

